CLINICAL STUDY

\title{
Aromatase expression in the normal human adult adrenal and in adrenocortical tumors: biochemical, immunohistochemical, and molecular studies
}

\author{
François Moreau ${ }^{1,2,3}$, Hervé Mittre ${ }^{1,2,4}$, Annie Benhaim ${ }^{1,2,4}$, Camille Bois ${ }^{1,2}$, Jérome Bertherat ${ }^{5}$, Serge Carreau $^{1,2}$ \\ and Yves Reznik ${ }^{1,2,6}$ \\ ${ }^{1}$ INRA USC 2006, 14032 Caen, France, ${ }^{2}$ Université de Caen, EA 2608, 14032 Caen, France, ${ }^{3}$ Hopital Civil, Service d'Endocrinologie et Maladies \\ Métaboliques, 67091 Strasbourg, France, ${ }^{4} \mathrm{CHU}$ Côte de Nacre, Département de Génétique et Reproduction, 14033 Caen, France, ${ }^{5}$ Service \\ d'Endocrinologie et Maladies Métaboliques, AP-HP Cochin, Paris, France and ${ }^{6} \mathrm{CHU}$ Côte de Nacre, Service d'Endocrinologie et Maladies Métaboliques, \\ 14033 Caen, France \\ (Correspondence should be addressed to Y Reznik at Department of Endocrinology, CHU Côte de Nacre, 14033 Caen Cedex, France; Email: reznik- \\ y@chu-caen.fr)
}

\begin{abstract}
Objective: The aromatase enzyme catalyzes the final stage of estrogen biosynthesis pathway from androgens. Its expression in the adrenal is poorly studied except for the rare estrogen-producing adrenocortical tumors. In order to further characterize aromatase expression in the adrenal, we evaluated the aromatase enzyme activity, Cyp19a1 gene expression level, and promoter utilization in normal adrenal tissues and in adrenocortical secreting tumors.

Design and methods: Six normal adult adrenals (NA), 2 feminizing adrenal tumors (FT), 10 cortisol-producing adenomas with overt (CS, $n=4$ ) or sub-clinical Cushing syndrome (SCS, $n=6)$ and 3 aldosterone-producing adenomas (APA) were studied. Tissue aromatase activity was determined by the tritiated $\left({ }^{3} \mathrm{H}\right)$-water method. Total aromatase mRNA were measured by a competitive RT-PCR. Promoter regions PII and PI.4-derived transcripts were also studied in NA, FT, and other steroid-producing tumors by a semi-quantitative comparative RT-PCR. Immunofluorescence analysis was performed in normal human adrenal tissues.

Results: Aromatase activity was detected in NA tissues and in all tumor subtypes, at high levels in both FT. In NA, aromatase immunofluorescence was detected in the cytoplasm of steroidogenic cells, mainly from zona reticularis. Compared with NA, aromatase transcript levels were similar in CS and APA, lower in SCS and similar or higher in FT. Promoter analysis suggested predominant PII utilization in NA, APA, and SCS, but similar PII and PI.4 utilization in CS tumors.

Conclusion: Aromatase is expressed at similar levels in normal adrenal and in adrenocortical tumors, but at variably high levels in FT. Different promoter utilization patterns are found among tumor subtypes.
\end{abstract}

European Journal of Endocrinology $16093-99$

\section{Introduction}

The enzyme cytochrome aromatase $\mathrm{P} 450$ is a microsomal protein that catalyzes the final stage of estrogen biosynthesis pathway from its androgen substrate. The aromatase is encoded by the Cyp19a1 gene characterized by several untranslated exons expression of which relies on alternative promoters submitted to a tissue-specific regulation (1). The enzyme is widely expressed in steroidogenic tissues such as gonads and placenta but also in adipose tissue, brain, and bone which are able to synthesize estrogens (2). There is indirect evidence that the normal human adrenal cortex is also a source for estrogen production $(3,4)$ but the molecular mechanisms assigned in such biosynthesis are still poorly characterized. Aromatase is expressed in the human adrenal medulla at all stages from postnatal until pubertal, but only the zona glomerulosa expresses the enzyme in the post-adrenarche period (5). Aromatase is overexpressed in feminizing adrenocortical tumors $(6-10)$ but its expression has not yet been investigated, to our knowledge, in non-feminizing tumors of adrenal origin. The aim of the present study was to evaluate the aromatase enzyme activity and Cyp19a1 gene expression level in the normal adrenal cortex and in adrenal feminizing tumors together with other steroid-producing adrenocortical tumors, in order to further characterize its expression.

\section{Design and methods}

\section{Ethical considerations}

The protocol for tissue collection and the experimental procedure were approved by the regional ethics committees, and written informed consent was obtained from the patients. 


\section{Adrenocortical tissue materials}

Normal adult adrenal (NA) tissues were obtained from patients undergoing expanded nephrectomy for kidney cancer $(n=6$, sex ratio $1: 1)$. All layers of the adrenal cortex were included in the molecular study, and were histologically normal. Tumor tissues were obtained from 15 adult patients with either an adrenal feminizing tumor (FT, $n=2, \mathrm{M} / \mathrm{F}$ sex ratio $1: 1$ ), a cortisolproducing adenoma associated with overt (CS, $n=4$, $\mathrm{M} / \mathrm{F}$ sex ratio1:3) or subclinical Cushing's syndrome (SCS, $n=6, \mathrm{M} / \mathrm{F}$ sex ratio $2: 1$ ) or an aldosteroneproducing adenoma (APA, $n=3, \mathrm{M} / \mathrm{F}$ sex ratio $0: 3$ ). Tumor tissues were obtained by surgery and immediately dissected by the pathologist. Adrenocortical fragments were rapidly frozen and stored at $-80{ }^{\circ} \mathrm{C}$ until enzyme assay or RNA extraction.

\section{Patients}

Patient FT1 was a 30-year-old male presenting with severe gynecomastia related to a $6 \times 5.5 \times 5 \mathrm{~cm}$ right adrenal tumor secreting estrone and estradiol at plasma concentrations respectively 5- and 2.5-fold higher than normal. The clinical and biochemical characteristics of patient FT1 were previously reported (10). Tumor mass was $100 \mathrm{~g}$, Weiss score staging was 3 (11), and McFarlane-Sullivan staging was II (12).

Patient FT2 was a 26-year-old female presenting with irregular menses, obesity, and hirsutism related to a 5-cm left adrenal tumor secreting cortisol (free urinary cortisol $1761 \mathrm{nmol} /$ day, normal range 55-275), testosterone (3.8 nmol/l, normal range $0.347-2.43)$, and estrogens (estrone $32081 \mathrm{pmol} / \mathrm{l}$, normal range 56-330, estradiol $36000 \mathrm{pmol} / \mathrm{l}$, normal range 30-170). Tumor mass was $50 \mathrm{~g}$, Weiss score staging was 3, and McFarlane-Sullivan staging was I. 17p13 loss of heterozygosity was not found in the tumor tissue.

Patients from CS group exhibited the typical features of Cushing's syndrome and high-plasma and urinary cortisol levels together with suppressed plasma ACTH levels. Patients from SCS group had no signs of Cushing's syndrome, normal basal plasma and urinary cortisol levels but exhibited non-suppressible plasma cortisol level after $1 \mathrm{mg}$ dexamethasone administration, morning ACTH plasma level in the low normal range and/or ipsilateral uptake on ${ }^{131}$ I-6 $\beta$-iodomethylnorcholesterol adrenal scintigraphy. The patients from APA group presented with hypertension, hypokalemia, elevated plasma and/or urinary aldosterone concentrations, and elevated aldosterone to active renin ratio.

\section{Aromatase activity assay}

We used the technique for aromatase activity assay previously described by Conley et al. (13). Microsomes from each tissue were prepared by successive ultracentrifugations. All procedures were carried out at $4{ }^{\circ} \mathrm{C}$ in buffer $0.1 \mathrm{M}$ phosphate, $\mathrm{MGCl}_{2} 5 \mathrm{mM}$, pH 7.4 . Protein concentrations in the preparations were determined according to Bradfford et al. (1976). Microsomal aromatase activity was evaluated by measuring ${ }^{3} \mathrm{H}_{2} \mathrm{O}$ released from $300 \mathrm{nM}\left(1 \beta-N-{ }^{3} \mathrm{H}\right)$ androst-4-ene-3,17-dione $(24 \mathrm{Ci} / \mathrm{mmol}$, New England Nuclear, PerkinElmer, Waltham, MA, USA) at $37^{\circ} \mathrm{C}$ for $3 \mathrm{~h}$. The microsomal protein was resuspended and diluted to $2 \mathrm{mg}$ protein $/ \mathrm{ml}$ in $0.1 \mathrm{M}$ phosphate buffer, $\mathrm{MGCl}_{2} 5 \mathrm{mM}$ (pH 7.4) containing $22 \mathrm{mM}$ ATP, $22 \mathrm{mM}$ NADP, 110 mM glucose-6-phosphate, 25 IU glucose-6phosphate dehydrogenase, $33 \mathrm{mM}$ NAD, and $0.8 \mathrm{nmol} / \mathrm{ml}$ androstenedione. The reaction was stopped by adding $3 \mathrm{ml}$ of ice cold chloroform in test tube and shaking vigorously. After centrifugation at $2000 \boldsymbol{g}$ for $5 \mathrm{~min}$, the chloroform layer was transferred in tube and the aqueous layer was re-extracted with further $3 \mathrm{ml}$ chloroform. Duplicate $0.4 \mathrm{ml}$ of aqueous phase was transferred into tubes containing $0.8 \mathrm{ml}$ of $5 \%$ dextran-coated charcoal suspension. Tubes were vortex mixed and incubated at $4{ }^{\circ} \mathrm{C}$ for $10 \mathrm{~min}$ then centrifuged at $2000 \mathrm{~g}$ for $15 \mathrm{~min}$. One milliliter supernatant from one tube was transferred into counting vial containing $3 \mathrm{ml}$ of liquid scintillator. Supernatant of the other tube was transferred into counting vial and evaporated before adding $3 \mathrm{ml}$ of liquid scintillator and the radioactivity value was taken as control and substracted. The vial's radioactivity was measured using a Tri-carb 1900CA liquid scintillation analyzer (Packard Instrument Co.). For all experiments, $1 \mathrm{mg}$ BSA was taken as blank and the value was subtracted.

\section{Aromatase mRNA quantification by RT-PCR}

Aromatase transcripts were measured in fragments from adrenal tumors and from four normal human adrenals. Total RNA were isolated according to the usual technique (14). The cDNAs obtained by retrotranscription with oligodT $\mathrm{T}_{12-18}$ were amplified by PCR using the primers described in Table 1. One of the primers was fluorescence labeled with the fluorophor FAM. PCR products were separated on an acrylamide gel and intensity of fluorescence was measured with the ABI377 sequencer (Applied Biosystem, Foster City, CA, USA). The quantitation of aromatase transcripts was performed as previously reported (15). The quantitation of GAPDH was performed in all samples and results were expressed by the amount of aromatase transcript divided by that of GAPDH transcript.

\section{PII and PI.4 aromatase promoters analysis}

PII and PI.4-derived transcripts were detected in the tumors by a qualitative comparative RT-PCR. The cDNAs were obtained using a specific antisense primer hybridizing on exon III of aromatase gene. Sense primers AroPII and AroPI.4 corresponding respectively to exon II and exon I.4 were used with the same 
Table 1 Sequence of the primers used for CYP 21 polymerase chain reaction.

\begin{tabular}{|c|c|}
\hline Aroi5fluo & 5 end sense oligo from exon $X$ \\
\hline & 5 GCTTTGAGAAGGATAGGCCTTCATTAAC 3 \\
\hline Aroi3 & $\begin{array}{l}3 \text { end antisense oligo from exon } X \\
5 \text { GCAAGTGGCTGAGGCATAAATCG } 3\end{array}$ \\
\hline Bene1fluo & $\begin{array}{l}5 \text { end sense oligo from GAPDH } \\
5 \text { TCATCCATGACAACTTTG } 3\end{array}$ \\
\hline Bene2 & $\begin{array}{l}3 \text { end antisense oligo from GAPDH } \\
5 \text { GTGCTCAGTGTAGCCCAGGATGC } 3\end{array}$ \\
\hline AroRev & $\begin{array}{l}3 \text { end antisense oligo from exon IV } \\
5 \text { CAGAGCTTTCATAAAGAAGGGTCGA } 3\end{array}$ \\
\hline Aro-PII & $\begin{array}{l}5 \text { end sense oligo from exon II } \\
5 \text { GGGGATTCTGTAATTTTTCTGTCCCT } 3\end{array}$ \\
\hline Aro-PI.4 & $\begin{array}{l}5 \text { end sense oligo from exon I.4 } \\
5 \text { GGCTCCAAGTAGAACGTGACCAACTG } 3\end{array}$ \\
\hline AroCom & $\begin{array}{l}3 \text { end antisense oligo from coding exon II } \\
5 \text { CAGCCCAAGTTTGCTGCCGAA } 3\end{array}$ \\
\hline
\end{tabular}

antisense primer AroCom as PCR primers to highlight transcripts depending on promoters II and I.4. Primers are detailed in Table 1. Promoter analysis of PCR products derived from exon PII and PI.4 were performed after a 30 and 40 cycle amplification respectively. PCR products were visualized on a 3\% non-denaturing agarose gel.

\section{Semi-quantitative comparison of PII and PI.4-derived transcripts}

A semi-quantitative comparison of PII and PI.4-derived transcript levels was made. Sense primers AroPII and AroPI.4 were used with the same antisense primer AroCom as PCR primers to quantitate the transcripts depending on promoter II and I.4. PII and PI.4-derived transcripts were co-amplified with the primers (AroComfluo; Aro-PII) and (AroCom-fluo; Aro-PI.4) respectively. AroComfluo corresponds to the primer AroCom labeled with the fluorophor FAM. PCR products migrated on acrylamide gel to allow measurement of fluorescence intensity of PCR products corresponding to transcript PII and transcript PI.4 using ABI377 (Applied Biosystem).

\section{Immunofluorescence analysis of human adrenal cortex}

Paraffin sections of $3 \mu \mathrm{m}$ thickness from adrenal tissues and ovarian follicle control tissues were dewaxed in toluene, then rehydrated through graded alcohols to water. Sections then underwent microwave antigen retrieval at full power in four $4 \mathrm{~min}$ cycles in $0.1 \mathrm{M}$ sodium citrate. After standing for $20 \mathrm{~min}$ at room temperature, the slides were washed in PBS for $3 \times$ $2 \mathrm{~min}$. The sections were incubated overnight at $4{ }^{\circ} \mathrm{C}$ with the monoclonal mouse anti-human aromatase (Serotec, France) diluted 1:50 in 3\% BSA in PBS as described previously (16). On the following day, the sections were washed with PBS and then incubated with texas red-labeled goat anti-mouse immunoglobulins (Santa Cruz, France) diluted 1:200 in PBS for $45 \mathrm{~min}$ at room temperature. After being washed with PBS, sections were coverslipped with mounting medium with DAPI (Santa Cruz, France). Control staining was performed on adjacent serial sections and consisted in replacing the primary antibody with PBS-BSA 3\%. Phase contrast electron microscopy allowed the localization of the different structural zonas of the human adrenal cortex.

\section{Statistical analysis}

The enzyme activity and the mRNA levels measured in the different adrenocortical fragments were compared by a non-parametric Mann-Whitney test. Level of significance was $P<0.05$. Linear correlation analysis was performed by Spearman test.

\section{Results}

\section{Aromatase enzyme activity}

Microsomal aromatase activity was detected in NA and in all tumor subtypes. In comparison with NA, the two FT showed high aromatase activity level, with a 7 - and 40-fold enhancement respectively (Fig. 1). In comparison with human follicle granulosa cell microsomes, aromatase activity detected in the FT1 $(780 \mathrm{fmol} / \mathrm{mg}$ prot/h) and FT2 (4656 fmol/mg prot/h) feminizing tumors were respectively $1 / 35$ and $1 / 6$ th (data not shown). Aromatase activity was detected at low level in all NA fragments (mean \pm s.e.M. $103 \pm 30.5 \mathrm{fmol} / \mathrm{mg}$ prot/h), and at a comparable level in adrenal samples from the CS, SCS, and APA secreting tumors (Fig. 1).

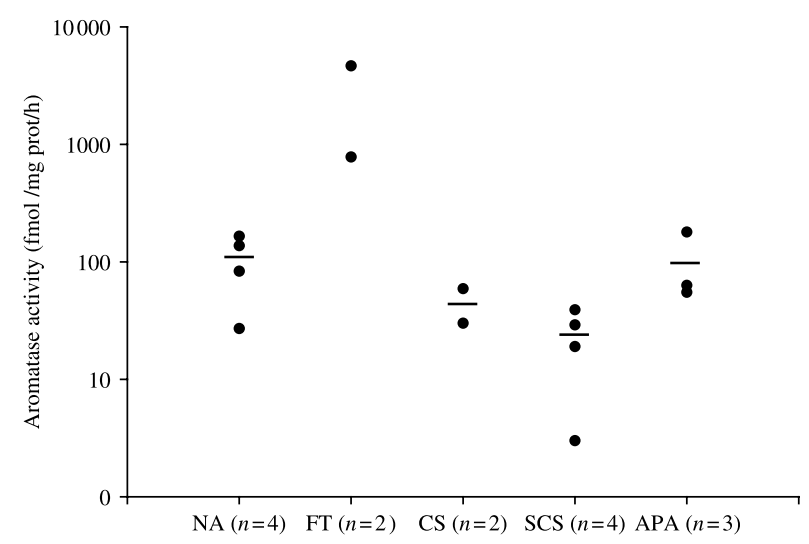

Figure 1 Aromatase activity in normal adrenal tissues, feminizing, and non-feminizing tumors. NA, normal adult adrenals; FT, feminizing tumors; CS, cortisol-producing adenomas with overt Cushing's syndrome; SCS, cortisol-producing adenomas with subclinical Cushing's syndrome; APA, aldosterone-producing adenomas. 


\section{Quantitative PCR analysis of Cyp19a1 mRNA}

Aromatase mRNA expressed as a ratio to GAPDH mRNA were detected in all samples from NA fragments and from adrenocortical tumor fragments. A large overexpression of aromatase mRNA was observed in FT2 but not in FT1 in comparison with NA fragments (respectively 135 and 0.12 vs $0.12 \pm 0.05$ (ARNm aromatase in amol/ARNm GAPDH in amol) $\times 10^{3}$; Fig. 2). In the non-feminizing tumors, variable transcript levels were observed in comparison with NA: a 2-fold increase of aromatase mRNA was measured in APA but the difference did not reach significance, and the CS group had a mean aromatase mRNA level comparable with that from NA. By contrast, the SCS group showed a significantly lower aromatase mRNA level in comparison to NA $(P<0.03$; Fig. 2). A strong and significant correlation $(r=0.67, P=0.039)$ was observed between aromatase activity and aromatase mRNA level in the tissue samples (data not shown).

\section{Aromatase promoter analysis}

PII and PI.4-derived transcripts were identified in both FT samples. FT1 expressed low levels of PI.4 derived transcripts. By contrast, FT2 expressed PII-derived transcripts at 5000-fold the level of PI-4. In the non-feminizing tumors, PII-derived transcripts were identified in all tumor groups while PI.4-derived transcripts were found in all except APA tumors (Fig. 3). The semi-quantitative comparison of PII and PI.4-derived transcript levels was established in a subset of normal adrenals $(n=2)$ and in different tumor subtypes. PII-derived transcripts were predominant in normal tissues, but also in SCS $(n=3)$ and APA $(n=3)$ tumors. By contrast, CS tumors $(n=2)$ exhibited a $1: 1$ PII/PI4 ratio (Fig. 4).

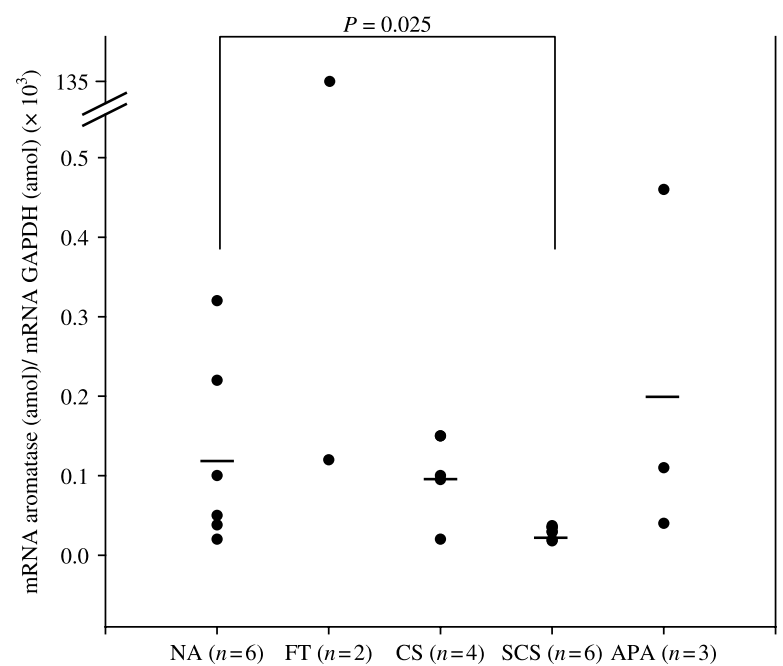

Figure 2 Aromatase transcripts expression in normal adrenal tissues, feminizing, and non-feminizing tumors.

\section{Immunofluorescence of normal human adrenal cortex}

Incubation of slices from normal human adult adrenocortical tissue with the aromatase antibody revealed the presence of immunoreactive material in adrenal steroidogenic cells with a weak and diffuse staining in the zona glomerulosa and zona fasciculata cells (Fig. 5A), and a more sustained staining in the zona reticularis (Fig. 5B). Aromatase immunostaing was also observed in control tissue from human ovarian follicle (data not shown). No immunostaining was observed in the medulla (data not shown). Control sections without primary antibody showed no staining (data not shown). The comparison of DAPI nuclear staining and aromatase staining sections showed a cytoplasmic localization of aromatase (Fig. 5A and B).

\section{Discussion}

The present study demonstrates not only the expression of aromatase in adrenal tissues from the normal gland but also from different adrenocortical tumors. Such expression was detected by two methods, i.e. enzyme activity and mRNA quantitation by RT-PCR. Estrogen production by the adrenal was suggested from studies performed in the 1970s demonstrating the adrenal contribution to circulating estrogens by adrenal vein sampling in normal women and in patients with congenital virilizing adrenal hyperplasia $(3,4,17)$. Cell culture experiments also suggested that normal human adrenal cells may produce estrone in vitro (18). More recent studies showed the presence of aromatase activity and/or aromatase transcripts in the normal adrenal gland $(5,6,9)$ but such results were not found by others $(8,19)$. Aromatase mRNA lacking exon five was also identified in normal human adrenal (20). The present study has
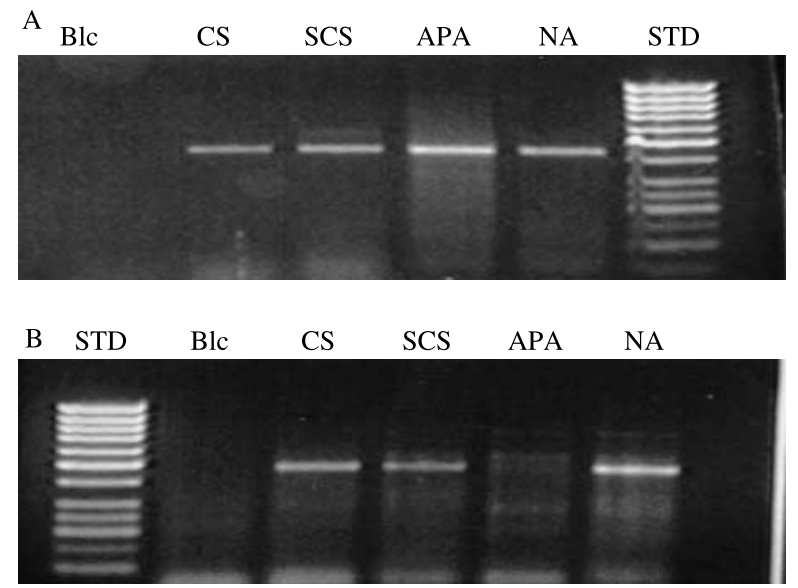

Figure 3 (A) PII-derived transcripts in normal adrenals and nonfeminizing tumors. (B) PI.4-derived transcripts in normal adrenal and non-feminizing tumors. Blc, Blank PCR; STD, 50 bp DNA ladder. 


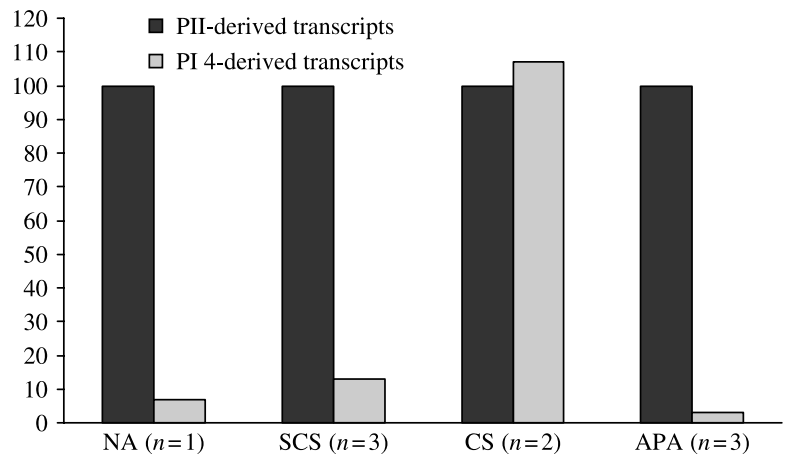

Figure 4 Relative amounts of PI.4-derived and PII-derived transcripts (arbitrarily defined as 100\%) in normal adrenal and non-feminizing tumors.

shown the presence of aromatase activity, although at low level, in normal adrenal tissues. Moreover, immunofluorescence experiments confirmed the presence of aromatase in the cytoplasm of steroidogenic cells from the different adrenocortical zonas, with a stronger expression in the zona reticularis than in both zona fasciculata and zona glomerulosa. We observed no aromatase immunostaining in the medulla from adult adrenal. The aromatase antiserum used in these experiments is a well characterized antibody that previously allowed identification aromatase expression in various mammalian gonadal and placental tissues, including the human ovarian follicle (16). Our results contrast with those from Baquedano et al. who found a marked aromatase immunostaining in prepubertal human adrenal medulla and in peripubertal zona glomerulosa (5).

Two FT were shown to exhibit a high aromatase activity in comparison with normal adrenal tissues. Previous studies utilizing the same technique for measuring aromatase activity demonstrated a marked aromatase overexpression in FT $(6-10,19)$. At the molecular level, aromatase transcripts were overexpressed in FT2 but not FT1, while moderately high level of enzyme activity was observed in the latter, a result possibly explained by a short half-life of aromatase mRNA in FT1. Weak aromatase overexpression in FT1 may explain the moderately high-circulating estrogen level that is possibly driven by androgen substrate excess and/or by a mass effect of the tumor. The level of aromatase expression in this FT probably reflects a lower degree of differentiation.

Promoter activity was also characterized in normal adrenocortical tissues and in estrogen-producing tumors. In both, promoter PII was the major transcript while PI.4 was weakly expressed confirming previous studies $(8-10,19)$.

The present study also questioned the presence of aromatase in adrenal tumors apart from the rare estrogen-producing tumors, which was suggested by studies based on adrenal vein catheterization in aldosterone and cortisol-producing tumors (21). We observed in a set of various steroid-secreting tumors that the enzyme activity and aromatase transcripts were detected in all tumors samples. Aldosterone and cortisol-producing adenomas showed similar aromatase expression levels compared with normal adrenal tissues. By contrast, adenomas associated with subclinical autonomous hypercortisolism had a lower level of aromatase expression. Such difference does not deserve an obvious explanation and may be confirmed in a larger group of tumors. The influence of gender and menopausal status on aromatase expression in adrenal tissues could not be investigated in the present study due to the small size of the tumor sample.

Promoter utilization was not uniformly distributed among non-estrogen tumors. Promoter PII was predominant in adenomas associated with aldosteronism or subclinical autonomous hypercortisolism. By contrast, both PII and PI.4 promoters were equally used in
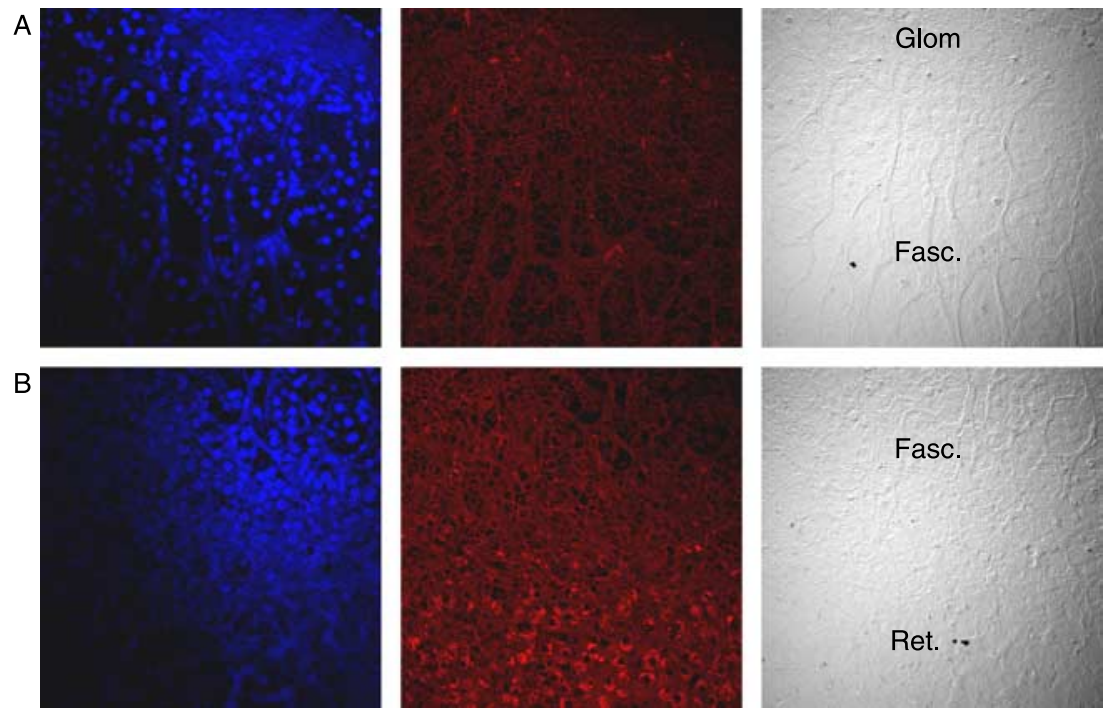

Figure 5 Immunofluorescence analysis of Cyp19a1 in normal human adrenocortical tissue $(\times 60)$. DAPI is localized in the nuclei of adrenocortical cells (left row). Immunostaining used an anti-mouse Cyp19a1 primary antiserum and a goat anti-mouse secondary antiserum (middle row). Phase contrast microscopy of the same section and HES coloration identifies the different zonas of the adrenal cortex (right row).

(A) immunostaining section, including zona glomerulosa and zona fasciculata.

(B) immunostaining section, including zona fasciculata and zona reticularis. Full colour version of this figure available via http://dx.doi.org/10.1530/EJE-08-0215 
adenomas associated with overt Cushing's syndrome. Aromatase proximal promoters are under a complex regulation through cAMP response element and steroidogenic factor-1 motifs in promoter PII and through glucocorticoid response element in promoter PI.4 (22, 23). A tissue-specific regulation of PI.4 expression by glucocorticoids was already demonstrated in normal adipose tissue and in leiomyoma tumors (24, 25 ). We hypothesize that the relative overexpression of PI.4 observed in adenomas associated with Cushing's syndrome may result from an activation of the PI.4 glucocorticoid response element induced by glucocorticoid excess. Such PI.4 overexpression was not observed in tumors associated with subclinical Cushing's syndrome, possibly due to the much lower level of glucocorticoid excess in the latter.

The physiological role of aromatase in the adrenal remains speculative. Aging is associated with a 2- to 4-fold increase of in vivo androstenedione to estrone conversion in postmenopausal women, and the adrenal gland may play a role in estrogen synthesis and exert some of its protective effects after menopause (26). Another key question lies in the possible proliferative effect of locally produced estrogens from adrenocortical tumors. Aromatase expression is dramatically enhanced in the stromal cells of female breast carcinoma suggesting that locally synthesized estrogens may act in a paracrine way to promote tumor growth (27). $\beta$-Estrogen receptors were identified in steroid-secreting adrenocortical tumors, and estrogens may thus induce adrenocortical cell proliferation (28). One may thus speculate on the implication of estrogen receptor expression in adrenocortical tumors, which should favor estrogen-induced proliferation. In this perspective, our study is limited by the small number of tumors that were investigated and by the absence of estrogen receptor quantitation.

In conclusion, our data demonstrate the presence of a functional aromatase enzyme in the normal adrenal gland but also in feminizing- and non-feminizingproducing adrenocortical tumors. The differential aromatase expression level and promoter utilization between tumor subtypes suggests complex regulating mechanisms that have to be further analyzed.

\section{Declaration of interest}

The authors declare that there is no conflict of interest that could be perceived as prejudicing the impartiality of the research reported.

\section{Funding}

This work was supported in part by a grant number from the Fondation pour la Recherche Médicale, Paris, France.

\section{Acknowledgements}

We thank Céline Bazille for her useful help in the preparation of the histology slides.

\section{References}

1 Sebastian S \& Bulun SE. A highly complex organization of the regulatory region of the human CYP19 (aromatase) gene revealed by the human genome project. Journal of Clinical Endocrinology and Metabolism 200186 4600-4602.

2 Simpson ER. Role of aromatase in sex steroid action. Journal of Molecular Endocrinology 200025 149-156.

3 Wasada T, Akamine Y, Kato K, Ibayashi H \& Nomura Y. Adrenal contribution to circulating estrogens in woman. Endocrinologia Japonica 197825 123-128.

4 Wajchenberg BL, Goldman J, Kyan TS, Achando SS, Thomsen YL \& Lima SS. Oestrogen dynamics in adrenal venous effluents in congenital virilizing adrenal hyperplasia. Clinical Endocrinology 198013 401-404.

5 Baquedano MS, Saraco N, Berensztein E, Pepe C, Bianchini M, Levy E, Goati J, Rivarola MA \& Belgorosky A. Identification and developmental changes of aromatase and estrogen receptor expression in prepubertal and pubertal human adrenal tissues. Journal of Clinical Endocrinology and Metabolism $2007 \mathbf{9 2}$ 2215-2222.

6 Kimura M, Itoh N, Tsukamoto T, Kumamoto Y, Takagi Y \& Mori Y. Aromatase activity in an estrogen-producing adrenocortical carcinoma in a young man. Journal of Urology 1995153 $1039-1040$

7 Goto T, Murakami O, Sato F, Haraguchi M, Yokoyama K \& Sasano H. Oestrogen producing adrenocortical adenoma: clinical biochemical and immunohistochemical studies. Clinical Endocrinology $199645643-648$.

8 Young J, Bulun ES, Agarwal V, Couzinet B, Mendelson CR, Simpson ER \& Schaison G. Aromatase expression in a feminizing adrenocortical tumor. Journal of Clinical Endocrinology and Metabolism 199681 3173-3176.

9 Phornphutkul C, Okubo T, Wu K, Harel Z, Tracy TF Jr, Pinar H, Chen S, Gruppuso PA \& Goodwin G. Aromatase P450 expression in a feminizing adrenal adenoma presenting as isosexual precocious puberty. Journal of Clinical Endocrinology and Metabolism 200186 649-652.

10 Bouraïma H, Lireux B, Mittre H, Benhaim A, Herrou M, Mahoudeau J, Guillon-Metz F, Kottler ML \& Reznik Y. Major hyperestrogenism in a feminizing adrenocortical adenoma despite a moderate overexpression of the aromatase enzyme. European Journal of Endocrinology 2003148 457-461.

11 Weiss LM. Comparative histologic study of 43 metastasizing and non metastasizing adrenocortical tumors. American Journal of Surgical Pathology 19848 163-169.

12 Sullivan M, Boileau M \& Hodges CV. Adrenal cortical carcinoma Journal of Urology 1978120 660-665.

13 Conley AJ, Corbin CJ, Hinshelwood MM, Liu Z, Simpson ER, Ford JJ \& Harada N. Functional aromatase expression in porcine adrenal gland and testis. Biology of Reproduction $1996 \mathbf{5 4} 497-505$.

14 Chomczynski P \& Sacchi N. Single-step method for RNA isolation by acid guanidium thiocyanate-phenol-chloroform extraction. Analytical Biochemistry 1987162 156-159.

15 Breard E, Roussel H, Lindet Y, Mittre H \& Leymarie P. Presence of exon I mRNA from CYP19 gene in human granulosa cells. Molecular and Cellular Endocrinology 1999154 187-190.

16 Turner KJ, Macpherson S, Millar MR, McNeilly AS, Williams K, Cranfield M, Groome NP, Sharpe RM, Fraser HM \& Saunders PTK. Development and validation of a new monoclonal antibody to mammalian aromatase. Journal of Endocrinology 2002 172 21-30.

17 Saez JM, Morera AM, Dazord A \& Bertrand J. Adrenal and testicular contribution to plasma oestrogens. Journal of Endocrinology 197255 41-49.

18 McKenna TJ, O'Connell Y, Cunningham S, McCabe M \& Culliton M. Steroidogenesis in an estrogen-producing adrenal tumor in a young woman: comparison with steroid profiles associated with cortisol and androgen-producing tumors. Journal of Clinical Endocrinology and Metabolism 199070 28-34. 
19 Watanabe T, Yasuda T, Noda H, Wada K, Kazukawa I, Someya T, Minamitani K, Minagawa M, Wataki K, Matsunaga T, Ohnuma N, Kohno Y \& Harada N. Estrogen secreting adrenal adenocarcinoma in an 18-month-old boy: aromatase activity, protein expression mRNA and utilization of gonadal type promoter. Endocrine Journal 200047 723-730.

20 Pepe CM, Saraco NI, Baquedano MS, Guercio G, Vaiani E, Marino R, Pandey AV, Flück CE, Rivarola MA \& Belgorosky A. The cytochrome P450 aromatase lacking exon 5 is associated with a phenotype of nonclassic aromatase deficiency and is also present in normal human steroidogenic tissue. Clinical Endocrinology $200767698-705$.

21 Yuen BH, Kelch RP \& Jaffe RB. Adrenal contribution to plasma oestrogens in adrenal disorders. Acta Endocrinologica $1974 \mathbf{7 6}$ 117-126.

22 Watanabe M \& Nakajin S. Forskolin up-regulates aromatase (CYP19) activity and gene transcripts in the human adrenocortical carcinoma cell line H295R. Journal of Endocrinology 2004 $180125-133$.

23 Zhao Y, Mendelson CR \& Simpson ER. Characterization of the sequences of the human CYP19 (aromatase) gene that mediate regulation by glucocorticoids in adipose stromal cells and fetal hepatocytes. Molecular Endocrinology 19959 340-349.

24 McTernan PG, Anderson LA, Anwar AJ, Eggo MC, Crocker J, Barnett AH, Stewart PM \& Kumar S. Glucocorticoid regulation of p450 aromatase activity in human adipose tissue: gender and site differences. Journal of Clinical Endocrinology and Metabolism 2002 87 1327-1336.

25 Shozu M, Sumitani H, Segawa T, Yang HJ, Murakami K, Kasai T \& Inoue M. Overexpression of aromatase P450 in leiomyoma tissue is driven primarily through promoter I4 of the aromatase P450 gene (CYP19). Journal of Clinical Endocrinology and Metabolism $2002872540-2548$.

26 Hemsell DL, Grodin JM, Brenner PF, Siiteri PK \& MacDonald PC. Plasma precursors of estrogen II. Correlation of the extent of conversion of plasma androstenedione to estrone with age. Journal of Clinical Endocrinology and Metabolism $1974 \mathbf{3 8}$ $476-479$.

27 Sasano H \& Harada N. Intratumoral aromatase in human breast endometrial and ovarian malignancies. Endocrine Reviews 1998 19 593-607.

28 Montanaro D, Maggiolini M, Recchia AG, Sirianni R, Aquila S, Barzon L, Fallo F, Ando S \& Pezzi V. Antiestrogens upregulate estrogen receptor $\beta$ expression and inhibit adrenocortical H295R cell proliferation. Journal of Molecular Endocrinology 200535 245-256.

Received 14 October 2008

Accepted 20 October 2008 